\section{Case Reports in Neurology}

Case Rep Neurol 2021;13:179-183

DOI: $10.1159 / 000513562$

Published online: March 18, 2021
(C) 2021 The Author(s)

Published by S. Karger AG Bas www.karger.com/crn

This article is licensed under the Creative Commons Attribution-NonCommercial 4.0 International License (CC BY-NC) (http://www.karger.com/Services/OpenAccessLicense). Usage and distribution for commercial purposes requires written permission.

\title{
Glioma with Leptomeningeal Spread Mimics Chronic Meningoencephalitis in a Young Adult
}

\author{
Ann-Kristin Becker ${ }^{a} \quad$ Marta Leonora Frank ${ }^{a} \quad$ Michael Friese $^{b}$ \\ Joachim Röther ${ }^{\mathrm{a}}$ \\ aDepartment of Neurology, Asklepios Klinik Altona, Hamburg, Germany; ${ }^{b}$ Department of \\ Neuropathology, Asklepios Klinik Nord, Hamburg, Germany
}

\section{Keywords}

Primary brain tumor $\cdot$ Glioblastoma $\cdot$ Leptomeningeal spread $\cdot$ Meningitis

\begin{abstract}
The most malignant type of intrinsic brain tumor is glioblastoma (WHO grade IV). Primary leptomeningeal spread is rare and leads to a variety of differential considerations, as there is no typical clinical or imaging pattern. Here we present a rare and uncommon case of a primary leptomeningeal glioblastoma in combination with a low-grade glioma in a 21-year-old male, initially presenting with only headache and lower back pain. The presented case illustrates the challenging differential considerations and the severe course of leptomeningeal glioblastomas.
\end{abstract}

\section{Introduction}

The most malignant type of intrinsic brain tumor is glioblastoma (WHO grade IV) [1]. In $20-25 \%$ of the cases, glioblastoma multiforme has leptomeningeal spread in the terminal stage of the disease [2]. Primary leptomeningeal spread is rare and leads to a variety of differential diagnoses. It mostly affects young adults, and there is no typical clinical or imaging 


\section{Case Reports in Neurology}

Case Rep Neurol 2021;13:179-183

\begin{tabular}{l|c|c|}
\hline DOI: 10.1159/000513562 & $\odot 2021$ The Author(s). Published by S. Karger AG, Basel
\end{tabular} www.karger.com/crn

Becker et al.: Leptomeningeal Glioma Mimics Meningoencephalitis

pattern. Bacterial or autoimmune meningitis is a frequent differential diagnosis that needs to be ruled out.

\section{Case Report}

A young farmer (21-year-old male) presented with parietooccipital headache and lower back pain. He had no further neurological deficits. A year previously, he had presented with an epileptic seizure, and cranial MRI had shown a frontal tumor, typical for a low-grade astrocytoma. A biopsy had been indicated, but the patient had refused further examinations at that time.

At this presentation, cerebrospinal fluid (CSF) analysis revealed a pleocytosis $(49 / \mu \mathrm{L})$ with massive elevation of protein $(>4 \mathrm{~g} / \mathrm{L})$ and lactate $(9.6 \mathrm{mmol} / \mathrm{L})$ levels. A tuberculous meningitis was suspected and tuberculostatic therapy initiated. MRI showed contrast enhancement in the perimedullary, cerebellar and cauda equina regions. Granulomatous inflammation, possibly due to tuberculosis or carcinomatosis, was presumed. All further diagnostics to exclude bacterial, viral, fungal or autoimmune disease, as well as a CSF cytology with FACS (fluorescence-activated cell sorting) analysis, showed no pathological results.

The patient developed a progressive brain stem syndrome with fluctuating left arm palsy and delirium. A biopsy of the tumor and the leptomeninx revealed edematous brain tissue with small fresh hemorrhages and slight, most likely reactive, astrogliosis with focal chronic inflammatory changes in the overlying leptomeninx. There was no immunohistochemical detection of an isocitrate dehydrogenase 1 (IDH1) mutation. It was only on the third biopsy of brain tissue that leptomeningeal cell proliferation with singular mitoses suspicious for a leptomeningeal neoplastic process was revealed.

The condition of the patient worsened, and he was subsequently resuscitated and intubated as a result of cardiopulmonary insufficiency and cardiac arrest. The patient died 3 months after admission.

The autopsy revealed atypical astrocytic differentiated cell clusters with moderate cell and nuclear polymorphism and with a low proliferation rate in the region of the suspected frontal tumor, corresponding to a low-level malignant diffuse astrocytoma (WHO grade II). A diffuse, malignant, astrocytically differentiated leptomeningeal glioma was found in the overlying meninges, compatible with a primary leptomeningeal glioblastoma of a diffuse type (WHO grade IV, IDH wild type) with tumor infiltration of the cerebral parenchyma and the cerebellar cortex (Fig. 1).

\section{Discussion}

We presented the case of a fulminant course of two gliomas of different entities (WHO grades II and IV) and locations (frontal and leptomeningeal). Gliomas form a group of primary tumors of the brain parenchyma with variations in severity and malignancy. A distinction is made into WHO grades I-IV. An IDH1/IDH2 mutation is characteristic for WHO grade II and III astrocytoma and oligodendroglioma and has a better prognosis than a wild-type IDH tumor [3]. Immunohistochemical detection of an IDH1/IDH2 mutation may help to differentiate between infiltrative astrocytoma cells and a reactive gliosis [4]. In the presented case, the diagnosis could only be established after multiple biopsies and was finally proven after an autopsy.

\section{Karger'=}




\section{Case Reports in Neurology}

\begin{tabular}{l|l}
\hline Case Rep Neurol 2021;13:179-183 \\
\hline DOI: 10.1159/000513562 & $\begin{array}{l}\text { @ 2021 The Author(s). Published by S. Karger AG, Basel } \\
\text { www.karger.com/crn }\end{array}$ \\
\hline
\end{tabular}

Becker et al.: Leptomeningeal Glioma Mimics Meningoencephalitis

There are only a few case reports describing a prolonged survival of patients with gliomas with primary leptomeningeal spread, usually as a result of radiation or systemic and intrathecal chemotherapy. Overall, the prognosis for leptomeningeal spread of cerebral gliomas is poor [5].

Differential diagnoses include chronic meningitis and meningoencephalitis. In immunocompetent patients, tuberculous meningitis is one of the most common causes of chronic meningitis. Typically, CSF reveals moderate pleocytosis with a markedly increased protein level and a reduced glucose level [6].

Apart from Mycobacterium tuberculosis, other bacterial (Treponema pallidum, borrelia, Listeria monocytogenes, Tropheryma whipplei), viral (HIV, herpesviruses, cytomegalovirus), mycotic (Cryptococcus neoformans, Cysticercus cellulosae) and parasitic causes (Strongyloides stercoralis) must be considered and excluded.

Among noninfectious causes, neoplastic forms such as meningeosis carcinomatosa or a primary cerebral lymphoma are the most common. However, even autoimmune diseases such as systemic lupus erythematosus or sarcoidosis may be associated with chronic meningoencephalitis with cerebral involvement [6].

\section{Conclusion}

The presented case illustrates the challenging differential considerations and the severe course of leptomeningeal glioblastomas. A primary leptomeningeal glioblastoma in combination with a low-grade glioma has not been previously reported. Due to the rareness of this finding, a causative genetic defect must be considered.

This case shows that histological confirmation of a diagnosis may require repeated attempts even by biopsy. Thus, if no cause of the meningitis can be found, repeated biopsy for diagnosis confirmation and detection of a tumor should be undertaken. Even though leptomeningeal spread of a glioma has a poor prognosis, most of the other differential diagnoses can still be treated.

\section{Statement of Ethics}

The research was conducted ethically in accordance with the World Medical Association Declaration of Helsinki. The mother of the case patient has given her written informed consent to publish his case (including publication of images).

\section{Conflict of Interest Statement}

All authors were previously employed at Asklepios Kliniken Hamburg at the time of the case. M.L. Frank is currently employed at Universitätsklinikum Hamburg-Eppendorf (since August 2020). Apart from their employment, M.L. Frank, A.-K. Becker, and M. Friese have no conflicts of interest to declare. J. Röther declares speaker fees from Bayer Vital, Bristol Myers Squibb, AstraZeneca, Amgen, and Pfizer related to topics on stroke research.

\section{Karger'}




\section{Case Reports in Neurology}

\section{Funding Sources}

The authors have no funding source relevant to this case report to declare.

\section{Author Contributions}

A.-K. Becker and M.L. Frank drafted the manuscript. Revision of the manuscript and scientific enrichment was performed by M. Friese and J. Röther. In addition, M. Friese conducted the histopathological examination.

\section{References}

1 Wesseling P, Capper D. WHO 2016 Classification of gliomas. Neuropathol Appl Neurobiol. 2018 Feb;44(2):139-50.

2 Erlich SS, Davis RL. Spinal subarachnoid metastasis from primary intracranial glioblastoma multiforme. Cancer. 1978 Dec;42(6):2854-64.

3 Appin CL, Brat DJ. Biomarker-driven diagnosis of diffuse gliomas. Mol Aspects Med. 2015 Nov;45:87-96.

4 Camelo-Piragua S, Jansen M, Ganguly A, Kim JC, Louis DN, Nutt CL. Mutant IDH1-specific immunohistochemistry distinguishes diffuse astrocytoma from astrocytosis. Acta Neuropathol. 2010 Apr;119(4):509-11.

5 Dardis C, Milton K, Ashby L, Shapiro W. Leptomeningeal metastases in high-grade adult glioma: development, diagnosis, management, and outcomes in a series of 34 patients. Front Neurol. 2014 Nov;5:220.

6 Helbok R, Broessner G, Pfausler B, Schmutzhard E. Chronic meningitis. J Neurol. 2009 Feb;256(2):168-75.

Ann-Kristin Becker and Marta Leonora Frank share principal authorship 


\section{Case Reports in Neurology}
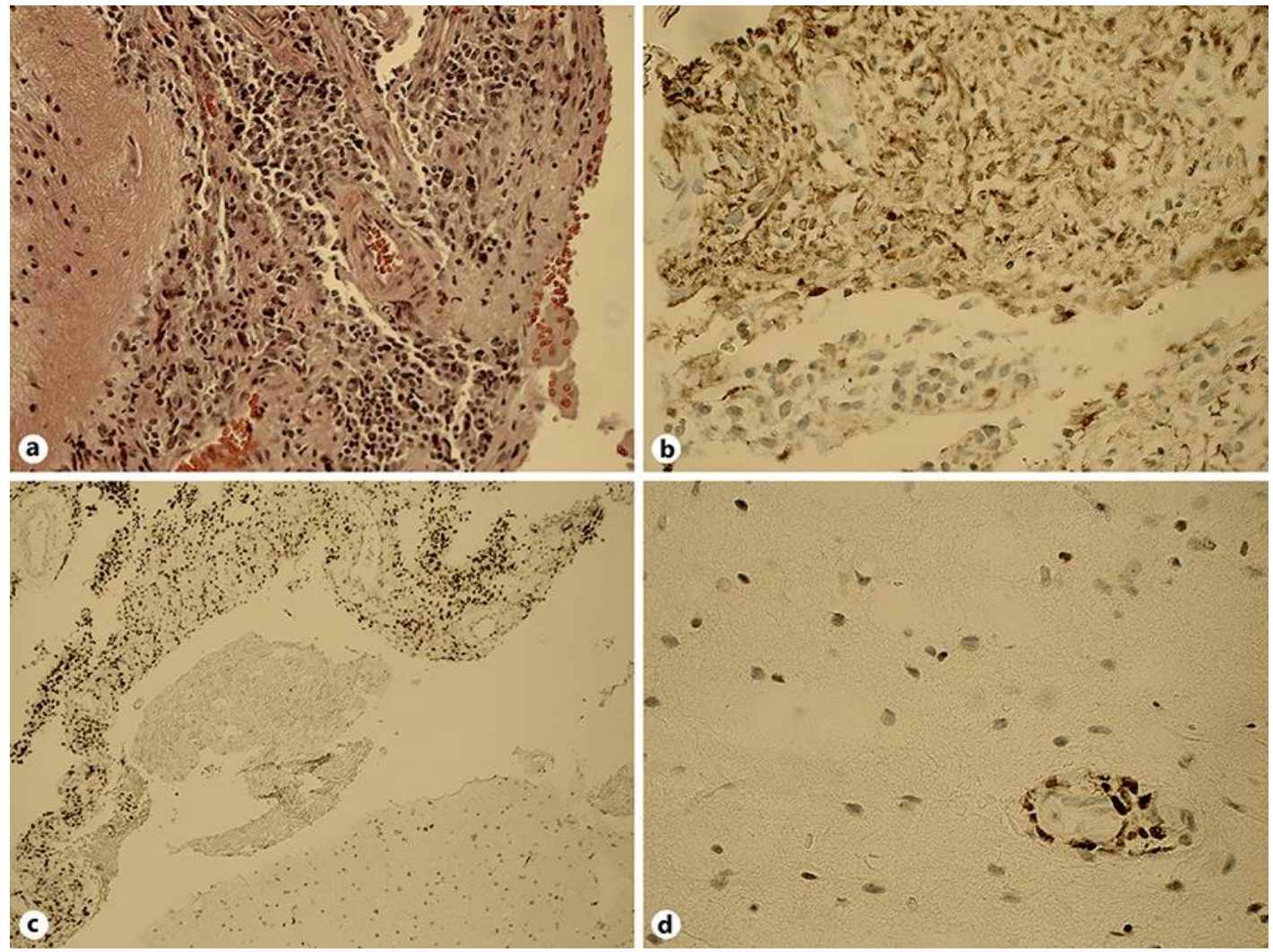

Fig. 1. Histopathological examination of the primary leptomeningeal glioblastoma. a Prominent tumor cell infiltrate in the subarachnoid space and reactive astrogliosis in the brain parenchyma. $\times 20$. Hematoxylin and eosin. $\mathbf{b}$ The astrocytic tumor cells are positive for glial fibrillary acid protein. $\times 40$. $\mathbf{c}$ Nearly all tumor cells are positive for the oncoprotein p53. $\times 10$. $\mathbf{d}$ The p53-positive tumor cells are spreading through the Virchow-Robin spaces throughout the brain. $\times 40$. 